\title{
Utilising biomass for renewable energy production: optimal profitability evaluation from different processing routes
}

\author{
Abdulhalim Abdulrazik ${ }^{1 *}$, Mohd Zulkifli Mohamad Noor ${ }^{1}$, Muhamad Fariz \\ Failaka $^{2}$, Marwen Elkamel ${ }^{3}$ and Ali Elkamel ${ }^{4}$ \\ ${ }^{1}$ Faculty of Chemical \& Natural Resources Engineering, Universiti Malaysia Pahang, \\ 26300 Gambang, Pahang, Malaysia \\ *Email: abdhalim@ump.edu.my \\ Phone: +6095492906; Fax: +605492889 \\ ${ }^{2}$ Department of Process and Energy Management, \\ PT Pupuk Kaltim, 75313 Bontang, Indonesia. \\ ${ }^{3}$ Department of Economics, University of Waterloo. N2L 3G1, Waterloo, Canada. \\ ${ }^{4}$ Department of Chemical Engineering, University of Waterloo, \\ N2L 3G1, Waterloo, Canada.
}

\begin{abstract}
Utilisation of biomass such as wheat straws for the renewable energy production is an attractive option for agricultural diversifications and sustainability targets. One of the possible energy products from wheat straws is bioethanol. Since bioethanol could be produced from different ways, the issue arises on how to select the most economical one. In this paper, four processing routes to convert the wheat straws into bioethanol were screened; i) pelletisation and gasification, ii) torrefied pelletisation and gasification, iii) dilute acidic hydrolysis and fermentation, and iv) concentrated acidic hydrolysis and fermentation. The objective was to develop optimisation models to evaluate these routes as find the one that would produce the highest annual profitability by considering the whole supply chain. A mathematical model for optimisation, classified as linear programming, was then formulated to consider the biomass blending requirements and profitability equation. Optimisation results showed that the conversion of wheat straws into bioethanol could be potentially exploited via the torrefied pelletisation and gasification route as they gave the highest profitability of $\$ 489,330$ per year, in the view of the whole supply chain. This was followed by concentrate acidic hydrolysis and fermentation route of $\$ 472,500$ per year, dilute acidic hydrolysis and fermentation route of $\$ 402,750$ per year, and pelletisation with gasification route of $\$ 388,530$ per year. The developed optimisation models have been successfully screened and selected the best processing route to produce bioethanol from the evaluated profitability. Since this was at the conceptual stage, further refinement of the model parameters will be needed to provide a more practical basis for comparison.
\end{abstract}

Keywords: Wheat straws, biomass; energy production; bioethanol processing routes; mathematical model; optimisation; supply chain.

\section{INTRODUCTION}

In dealing with biomass from agricultural residues, such as wheat straws, technological advancements have made them possible to be used as manufacturing feedstocks. Various 
kind of products could be manufactured including bioethanol. Georgieva et al. [1] reported that the wheat straws are the second world largest agricultural residues and one of the most important global lignocellulosic feedstocks for bioethanol production. Like the other cases of agricultural-based biomass resource utilisations, conversions of wheat straw to bioethanol are being practiced as diversification businesses for the farmers as well as an effort to achieve sustainability targets. Lignocellulosic feedstocks are basically fibrous or non-starch parts of the plants and have been long identified as a potential substitution to the non-renewable fossil-based feedstocks due to their important attributes, such as renewable, carbon neutral, abundant, and ubiquitous almost everywhere according to several authors, such as [2], [3], [4], and [5]. He and Zhang [2] also added that conventional ethanol or bioethanol production processes come from two routes; i) hydrolysis and fermentation of grain and sugar, and ii) hydration of ethylene from petroleum. Both processing routes are not sustainable because the former in which the feedstocks have created unwelcomed competitions with food and feed markets, while the latter in which the feedstocks are essentially not renewable. To overcome these issues, alternative productions of ethanol from lignocellulosic biomass have been proposed by [6]. Hence, two thermochemical processing routes; i) pelletisation and gasification, and ii) torrefied palletisation and gasification, and two biochemical processing routes; iii) dilute acidic hydrolysis and fermentation, and iv) concentrate acidic hydrolysis and fermentation of wheat straws for manufacturing bioethanol are the processes to be considered in this study. However, as stressed by [7], efforts are now focused to find the low cost and large scale conversion processes. Today, the four selected processing routes serve no clue on which one is the most attractive economically. Furthermore, this economic evaluation will be realistic if it is based on the whole supply chain from feed preparations to the finished products [8]. The supply chain in this regard is important due to the unfavourable characteristic of biomass, such as geographically dispersed, competing uses, and the derived products from biomass must remain competitive.

The optimal wheat straw to bioethanol supply chains model has been studied by several authors. These include the hybrid gasification and fermentation processes of wheat straw to bio-ethanol by [9], economic, political and environmental considerations for wheat straw-to-bioethanol by [10], Life-Cycle Assessment (LCA) approach for evaluating wheat straw to bioethanol pathways by [11], and a combination of production and logistic models for minimum cost target by [12]. In the whole supply chain, blending process was included as it is imperative to blend the wheat straw for feedstocks preparation due to the fact that this biomass resource is seasonal and varies physically and chemically. In addition, prior to blending, Demirbas [13] and Basu [14] reported that the range of testing and analyses for any biomass feedstocks including wheat straw comprise the heating value, particle size distribution, density, proximate analysis, ultimate analysis, and ash elemental analysis. Therefore, this study intends to develop the mathematical models for optimising and evaluating four processing routes of bioethanol production from three types of wheat straws with the addition of blending process and its requirements in the supply chain. Optimality in this context was referred to the feedstocks blending and the annual profitability.

\section{METHODS AND MATERIALS}

Overall methodology is shown in Figure 1 and three wheat straws with different qualities were selected. Comparisons in terms of annual profitability were applied for both thermochemical and biochemical conversion processes. Having said that, mathematical 
models with different parameters for supply chain optimisation were developed that have accounted for the bioethanol's revenue, the costs of wheat straws, and the specific production costs. For the thermochemical routes, the profitability of the supply chain for wheat straw pelletisation and torrefaction as the pre-treatment schemes for gasification were done while for biochemical routes, the same were applied for acidic hydrolyses with different concentrations as the pre-treatment schemes for fermentation.

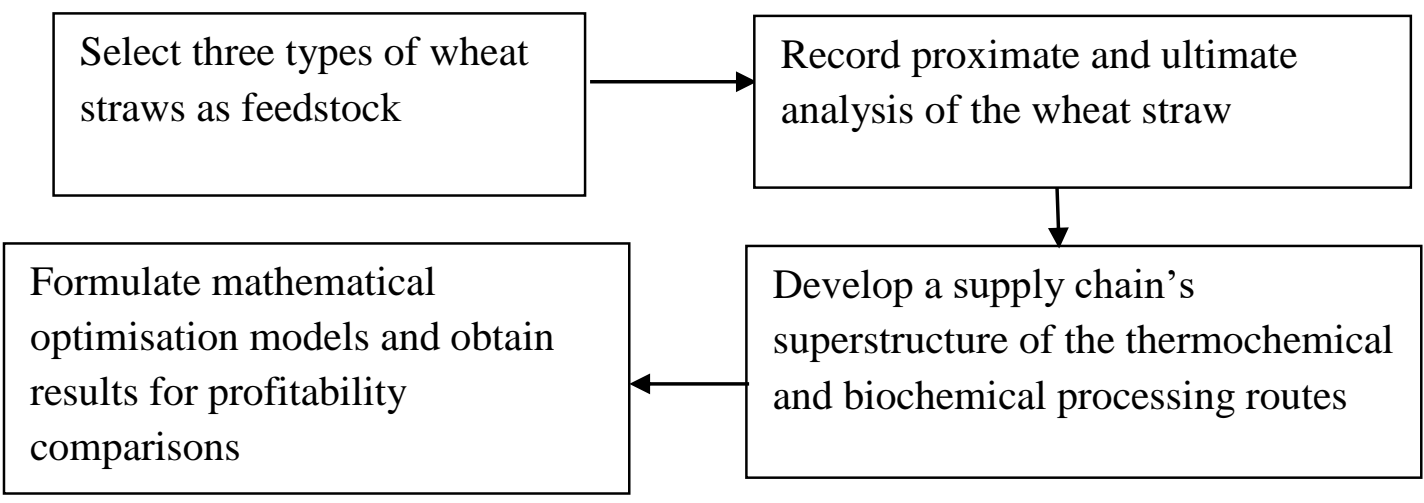

Figure 1. Overall methodology.

Table 1. Proximate analysis of wheat straws ([15], [16], and [17]).

\begin{tabular}{lccc}
\hline Proximate Analysis & Wheat Straw 1 & Wheat Straw 2 & Wheat Straw 3 \\
\hline Volatile Matter (\% wt dry basis) & 63.0 & 71.3 & 75.3 \\
Fixed Carbon (\% wt dry basis) & 23.5 & 19.8 & 17.7 \\
Ash (\% wt dry basis) & 13.5 & 8.9 & 7.0 \\
\hline
\end{tabular}

Table 2. Ultimate analysis of wheat straws ([15], [16], and [17]).

\begin{tabular}{lccc}
\hline Ultimate Analysis & Wheat Straw & Wheat Straw & Wheat Straw \\
& 1 & 2 & 3 \\
\hline C (\% wt dry basis) & 45.5 & 43.2 & 44.9 \\
H (\% wt dry basis) & 5.1 & 5.0 & 5.5 \\
N (\% wt dry basis) & 1.8 & 0.6 & 0.4 \\
O (\% wt dry basis) & 34.1 & 39.4 & 41.8 \\
Others (S, Cl, Residues) (\% wt dry & 13.5 & 11.8 & 7.4 \\
basis) & & & \\
Calculated Hydrogen-to-Carbon & 0.1121 & 0.1157 & 0.1225 \\
Ratio & & & \\
\hline
\end{tabular}

Table 1 and Table 2 show wheat straw proximate analysis and ultimate analysis, respectively. The proximate analysis provides composition information of biomass in terms of its gross components, such as volatile matter, fixed carbon, and ash contents. The ultimate analysis gives information about biomass elemental compositions, such as carbon, hydrogen, nitrogen, and oxygen. Table 3 meanwhile shows blending requirements for thermochemical and biochemical routes. To use the blended wheat straw as a solid fuel in the thermochemical routes, the ratio of hydrogen to carbon contents must be kept low so that the calorific value of the fuel is high. While for the biochemical routes, 
keeping the ash contents low was targeted as the main constituents in the ash are silica, aluminium, iron and, calcium which otherwise would lower hydrolysis and fermentation process efficiencies. In practice, both thermochemical and biochemical routes require more complex and careful requirements of the feedstocks but the ones stated in Table 3 are considered essential in this study to demonstrate the model's applicability.

Table 3. Desired wheat straw blending qualities based on proximate and ultimate analyses for bio-ethanol production ([18] and [19]).

\begin{tabular}{cc}
\hline Conversion Route & Feedstock Requirement \\
\hline Thermochemical & Keep H/C Ratio Low \\
Biochemical & Keep Ash Content Low \\
\hline
\end{tabular}

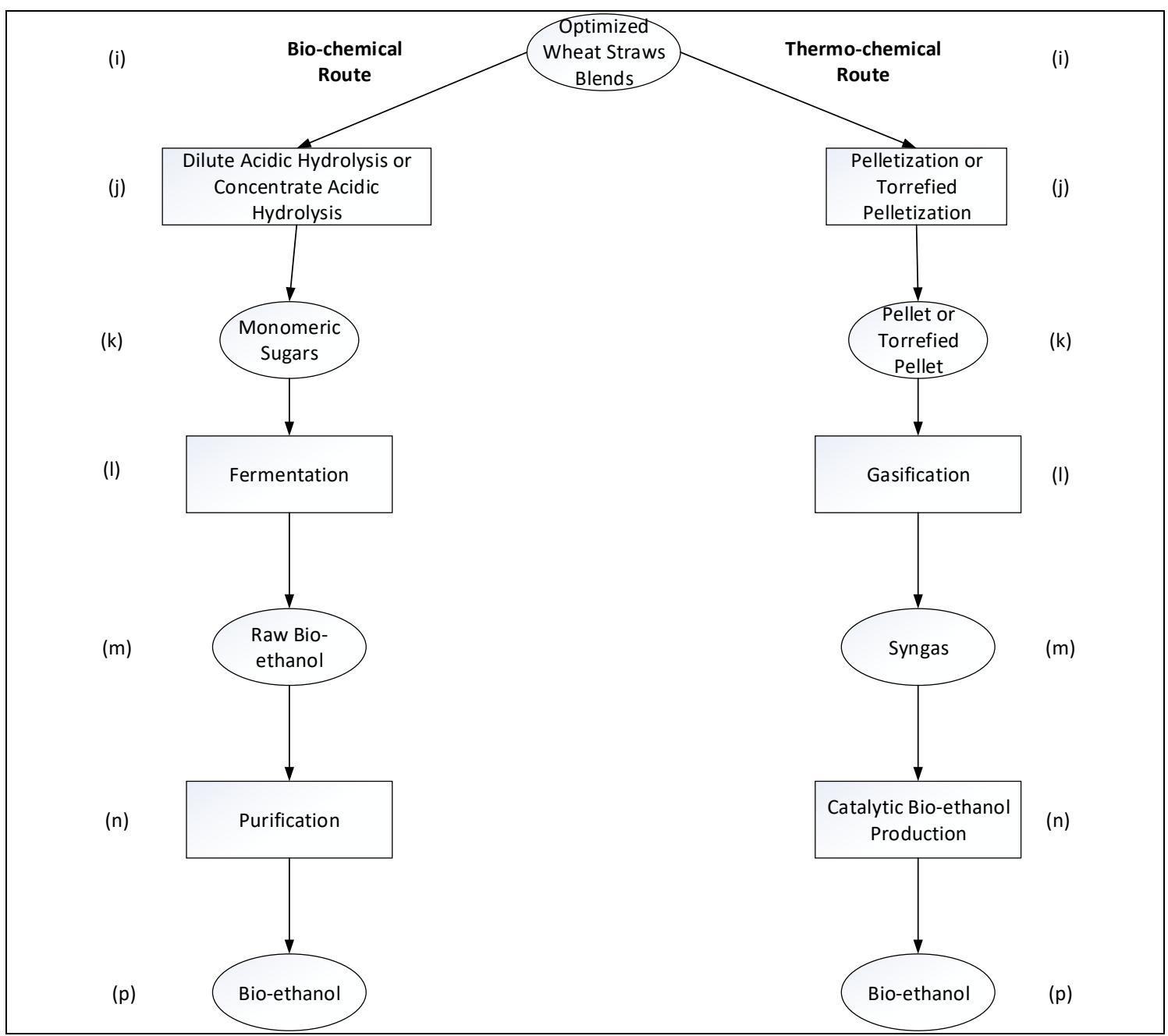

Figure 2. Superstructure of wheat straw-to-bioethanol supply chain.

Figure 2 shows the superstructure of wheat straw-to-bioethanol supply chain employed in this study. The superstructure serves as an important reference point in modelling the optimisation problem. Detailed steps about constructing such superstructure are well explained by [20], while the aim of this study is not to discuss such details but rather to present a generalised optimisation model that captures processing routes of the wheat straw to bioethanol problem. The small letter from $i$ to $p$ in Figure 2 represent each product and stage in the supply chain and will be used as an 
index in the model formulation. Circle and rectangular shapes act as storages and processes, respectively, while the downward arrows depict the sequences.

\section{Model Formulation}

Formulating the optimisation models in this study were divided into two parts; i) minimisation of the hydrogen-to-carbon ratio for thermochemical route and minimisation of ash content for the biochemical route, and ii) maximisation of annual profit. For the first part, the model was written as follows;

$$
\begin{gathered}
\text { Minimise Hydrogen Carbon Ratio }(H C R)=\text { minimise }\left(\sum_{w s s=1}^{3} x_{w s s} * H C R_{w s s}\right) \\
\text { Minimise Ash Content }(A C)=\text { minimise }\left(\sum_{w s s=1}^{3} x_{w s s} * A C_{w s s}\right)
\end{gathered}
$$

WSS denotes the wheat straw sources, and as stated in Table 4, they could come from three types or sources, and $x$ denotes the amount. These three types of wheat straws were arbitrary, which means they could be from three different origins or the same origin but with different qualities. Next, Equation (1) was applicable for thermochemical route while Equation (2) will be applicable for the biochemical route. Both Equation (1) and (2) resulted in an optimal blending of these three wheat straw sources and are constrained by the availabilities and the total input for the two pathways. For every route; i) pelletisation and gasification, ii) torrefied pelletisation and gasification, iii) dilute acidic hydrolysis and fermentation, and iv) concentrate acidic hydrolysis and fermentation), the total input was assumed to be the same: i.e., 14400 tonne/year or 2 tonnes/hour for 7200 working hours per year. Table 4 also shows the availabilities of wheat straw sources and costs. The wheat straw cost may vary depending on the physical and chemical properties, delivered shapes, distances between the farm's locations and the bioethanol processing facilities. However, in this study, the cost was considered to be $\$ 85 /$ tonne and was independent of the factors highlighted above. The other objective function considered in this study deals with profit maximisation. Therefore, economic parameters and conversion factors which will be used to calculate yield, are assembled and tabulated in Table 5 to Table 11. Specific production cost indicates the combination of capital and operating cost per tonne of product produced. Conversion factor meanwhile was used to show how much of the input would be transformed into the desired product.

Table 4. Data for Estimated Wheat Straw Cost [21].

\begin{tabular}{lcc}
\hline Wheat Straw Source & Availability (Tonne/year) & Wheat Straw Cost (\$/tonne) \\
\hline Wheat Straw 1 & 3600 & 85 \\
Wheat Straw 2 & 7500 & 85 \\
Wheat Straw 3 & 4800 & 85 \\
\hline
\end{tabular}

For Table 5, the selling price for the bio-ethanol would be used to determine the annual revenue while the demand was converted into a unit of tonne/year. Specific production costs (as shown in Table 6, 8, and 10) are referring to the cost to produce one unit tonnes of product at each processing stage $(j, l$, and $n$ ). Conversion factors (as shown in Table 7, 9, and 11) are referring to the production efficiencies, defined as the mass ratio of output to the input. 
Table 5. Bio-ethanol selling price and demand [22].

\begin{tabular}{cccc}
\hline $\begin{array}{c}\text { Selling Price } \\
(\$ / \text { liter })\end{array}$ & $\begin{array}{c}\text { Selling Price } \\
\text { (\$/tonne) }\end{array}$ & $\begin{array}{c}\text { Demand } \\
\text { (litre/year) }\end{array}$ & $\begin{array}{c}\text { Demand } \\
\text { (Tonne/year) }\end{array}$ \\
\hline 0.75 & 950 & $1 \times 10^{6}$ & 790 \\
\hline
\end{tabular}

Table 6. Specific production cost factor of $k$ at $j$ ( [23], [24], and [22]).

\begin{tabular}{|c|c|c|c|}
\hline Blended Wheat Straws, $i$ & Pre-treatment, $j$ & $\begin{array}{l}\text { Pre-treated } \\
\text { Product, } k\end{array}$ & $\begin{array}{c}\text { Cost } \\
\text { \$/Tonne }\end{array}$ \\
\hline $\begin{array}{l}\text { Blended Wheat Straws } 1 \\
\text { of Route } \mathrm{i}\end{array}$ & Pelletisation & Pellet & 90 \\
\hline $\begin{array}{l}\text { Blended Wheat Straws } 2 \\
\text { of Route ii }\end{array}$ & $\begin{array}{l}\text { Torrefaction and } \\
\text { Pelletisation }\end{array}$ & Torrefied Pellet & 100 \\
\hline $\begin{array}{l}\text { Blended Wheat Straws } 3 \\
\text { of Route iii }\end{array}$ & $\begin{array}{ll}\text { Dilute } & \text { Acidic } \\
\text { Hydrolysis } & \end{array}$ & $\begin{array}{l}\text { Monomeric } \\
\text { Sugars }\end{array}$ & 80 \\
\hline $\begin{array}{l}\text { Blended Wheat Straws } 4 \\
\text { of Route iv }\end{array}$ & $\begin{array}{l}\text { Concentrate Acidic } \\
\text { Hydrolysis }\end{array}$ & $\begin{array}{l}\text { Monomeric } \\
\text { Sugars }\end{array}$ & 90 \\
\hline
\end{tabular}

Table 7. Conversion factor of $k$ at $j$ ([8] and [25]).

\begin{tabular}{lllc}
\hline $\begin{array}{l}\text { Blended Wheat Straws, } \\
i\end{array}$ & Pre-treatment, $j$ & $\begin{array}{l}\text { Pre-treated } \\
\text { Product, } k\end{array}$ & $\begin{array}{c}\text { Conversion } \\
\text { Factor }\end{array}$ \\
\hline $\begin{array}{l}\text { Blended Wheat Straws } \\
1 \text { of Route i }\end{array}$ & Pelletisation & Pellet & 0.85 \\
$\begin{array}{l}\text { Blended Wheat Straws } \\
\text { 2 of Route ii }\end{array}$ & $\begin{array}{l}\text { Torrefaction and } \\
\text { Pelletisation }\end{array}$ & Torrefied Pellet & 0.75 \\
$\begin{array}{l}\text { Blended Wheat Straws } \\
\text { Blended Whii }\end{array}$ & $\begin{array}{l}\text { Dilute Acidic } \\
\text { Hydrolysis }\end{array}$ & $\begin{array}{l}\text { Monomeric } \\
\text { Sugars1 }\end{array}$ & 0.65 \\
4 of Route iv & $\begin{array}{l}\text { Concentrate Acidic } \\
\text { Hydrolysis }\end{array}$ & $\begin{array}{l}\text { Sugars2 } \\
\text { Straws }\end{array}$ & 0.70 \\
\hline
\end{tabular}

Table 8. Specific production cost factor of $m$ at $l$ ([22] and [26]).

\begin{tabular}{|c|c|c|c|}
\hline Pre-treated Product, $k$ & Main Processing, $l$ & $\begin{array}{l}\text { Intermediate Product, } \\
m\end{array}$ & $\begin{array}{c}\text { Cost } \\
\text { \$/Tonne }\end{array}$ \\
\hline Pellet of Route i & Gasification 1 & Bio-Syngas1 & 170 \\
\hline $\begin{array}{l}\text { Torrefied Pellet of Route } \\
\text { ii }\end{array}$ & Gasification 2 & Bio-Syngas2 & 170 \\
\hline $\begin{array}{l}\text { Monomeric Sugars } 1 \text { of } \\
\text { Route iii }\end{array}$ & Fermentation 1 & Raw Bio-ethanol1 & 150 \\
\hline $\begin{array}{l}\text { Monomeric Sugars } 2 \text { of } \\
\text { Route iv }\end{array}$ & Fermentation 2 & Raw Bio-ethanol2 & 150 \\
\hline
\end{tabular}

Since the aim of this study was to compare annual profitability, each of the routes will use the same mathematical expressions. The objective function was defined as; 
where, Equation (3) was detailed by the following Equation (4) to (6). $Q p$ is the amount of bioethanol stored for selling, FIJ is the amount of wheat straw blend that will be sent to pre-treatment facilities in tonne/year, $F K L$ is the amount of pre-treated product that will be sent to main processing facilities in tonne/year, $F M N$ is the amount of intermediate product that will be sent to final processing facilities in tonne/year, $S C F J$ is the specific production cost at pre-treatment facilities in $\$$ per tonne of pre-treated product produced, $S C F L$ is the specific production cost at main processing facilities in $\$$ per tonne of intermediate product produced, and $S C F N$ is the specific production cost at final processing facilities in $\$$ per tonne of final product produced.

Table 9. Conversion factor of $m$ at $l$ ([25] and [27]).

\begin{tabular}{lllc}
\hline Pre-treated Product, $k$ & $\begin{array}{l}\text { Main } \\
\text { Processing, } l\end{array}$ & $\begin{array}{l}\text { Intermediate } \\
\text { Product, } m\end{array}$ & $\begin{array}{c}\text { Conversion } \\
\text { Factor }\end{array}$ \\
\hline Pellet of Route i & Gasification 1 & Bio-Syngas1 & 0.75 \\
Torrefied Pellet of Route ii & Gasification 2 & Bio-Syngas2 & 0.85 \\
$\begin{array}{l}\text { Monomeric Sugars 1 of } \\
\text { Route iii }\end{array}$ & Fermentation 1 & Raw Bio-ethanol1 & 0.55 \\
$\begin{array}{l}\text { Monomeric Sugars 2 of } \\
\text { Route iv }\end{array}$ & Fermentation 2 & Raw Bio-ethanol2 & 0.55 \\
\hline
\end{tabular}

Table 10. Specific production cost factor of $p$ at $n$ ( [22] and [28]).

\begin{tabular}{lllc}
\hline Intermediate Product, $m$ & Final Processing, $n$ & Final Product, $p$ & $\begin{array}{c}\text { Cost } \\
\$ / \text { Tonne }\end{array}$ \\
\hline Bio-Syngas 1 of Route i & $\begin{array}{l}\text { Bio-ethanol } \\
\text { Production 1 } \\
\text { Bio-ethanol } \\
\text { Production 2 }\end{array}$ & Bio-ethanol 1 & 150 \\
$\begin{array}{l}\text { Bi } \\
\text { Raw Bio-Syngas 2 of Route } \\
\begin{array}{l}\text { Route iii } \\
\text { Raw Bio-ethanol 2 of } \\
\text { Route iv }\end{array}\end{array}$ & $\begin{array}{l}\text { Purification 1 } \\
\text { Purification 2 }\end{array}$ & Pure Bio-ethanol 1 & 150 \\
\hline
\end{tabular}

Table 11. Conversion factor of $p$ at $n$ ( [25] and [29]).

\begin{tabular}{lllc}
\hline Intermediate Product, $k$ & Final Processing, $l$ & Final Product, $m$ & $\begin{array}{c}\text { Conversion } \\
\text { Factor }\end{array}$ \\
\hline Bio-Syngas 1 of Route i & $\begin{array}{l}\text { Bio-ethanol } \\
\text { Production 1 } \\
\text { Bio-ethanol } \\
\text { Bio-Syngas 2 of Route ii }\end{array}$ & Bio-ethanol 1 & 0.73 \\
$\begin{array}{l}\text { Raw Bio-ethanol 1 of Route } \\
\text { iii }\end{array}$ & Purification 1 & $\begin{array}{l}\text { Purified Bio- } \\
\text { ethanol 2 }\end{array}$ & 0.73 \\
$\begin{array}{l}\text { Raw Bio-ethanol 2 of Route } \\
\text { iv }\end{array}$ & Purification 2 & $\begin{array}{l}\text { Purified Bio- } \\
\text { ethanol 2 }\end{array}$ & 0.95 \\
\hline
\end{tabular}

Total Sales of Bioethanol $=\sum_{p=1}^{P} Q_{p} *$ Bioethanol Selling Price

Total Wheat Straw Cost $=\sum_{i=1}^{I} \sum_{j=1}^{J} F I J_{i, j} *$ Wheat Straw Cost 
Total Specific Production Cost $=\left(\sum_{i=1}^{I} \sum_{j=1}^{J} F I J_{i, j} * \sum_{j=1}^{J} \sum_{k=1}^{K} S C F J_{j, k}\right)+$ $\left(\sum_{k=1}^{K} \sum_{l=1}^{L} F K L_{k, l} * \sum_{l=1}^{L} \sum_{m=1}^{M} S C F L_{l, m}\right)+\left(\sum_{m=1}^{M} \sum_{n=1}^{N} F M N_{m, n} * \sum_{n=1}^{N} \sum_{p=1}^{P} S C F N_{n, p}\right)$

In calculating the product yields (pre-treated, intermediate, and final product of each route), the following Equation (7) to (10) are used.

$$
\begin{gathered}
\left(\sum_{i=1}^{I} \sum_{j=1}^{J} F I J_{i, j} * \sum_{j=1}^{J} \sum_{k=1}^{K} \operatorname{COVJ}_{j, k}\right)=\sum_{k=1}^{K} \sum_{l=1}^{L} F K L_{k, l} \\
\left(\sum_{k=1}^{K} \sum_{l=1}^{L} F K L_{k, l} * \sum_{l=1}^{L} \sum_{m=1}^{M} \operatorname{COVL}_{l, m}\right)=\sum_{m=1}^{M} \sum_{n=1}^{N} F M N_{m, n} \\
\left(\sum_{m=1}^{M} \sum_{n=1}^{N} F M N_{m, n} * \sum_{n=1}^{N} \sum_{p=1}^{P} \operatorname{COVN}_{n, p}\right)=\sum_{n=1}^{N} \sum_{p=1}^{P} F N P_{n, p} \\
\sum_{n=1}^{N} \sum_{p=1}^{P} F N P_{n, p}=\sum_{p=1}^{P} Q_{p}
\end{gathered}
$$

In these equations, $C O V J$ is the conversion factor at pre-treatment facilities, $C O V L$ is the conversion factor at the main processing facilities, COVN is the conversion factor at the final processing facilities, and $F N P$ is the amount of bio-ethanol sent to product storage in tonne per year, which equals to the value of $Q p$. The constraints for this part are written as follows:

$$
\begin{aligned}
& \sum_{i=1}^{I} \sum_{j=1}^{J} F I J_{i, j}=14400 \\
& \sum_{p=1}^{P} Q_{p} \geq \text { Demand of Bioethanol }
\end{aligned}
$$

\section{RESULTS AND DISCUSSION}

The first part of the model was to meet the blending requirement while the second part was considered profit maximisation and comparison of profitability between the four

\begin{tabular}{|c|c|c|c|c|}
\hline Feedstock Requirement & $\begin{array}{l}\text { Wheat Straw } 1 \\
\text { (Tonne/year) }\end{array}$ & $\begin{array}{l}\text { Wheat Straw } 2 \\
\text { (Tonne/year) }\end{array}$ & $\begin{array}{l}\text { Wheat Straw } 3 \\
\text { (Tonne/year) }\end{array}$ & $\begin{array}{l}\text { Total } \\
\text { (Tonne/year) }\end{array}$ \\
\hline $\begin{array}{l}\text { Optimised Blends of } \\
\text { Wheat Straws } \\
\text { Thermochemical Routes } \\
\text { (Route i and Route ii) }\end{array}$ & 3600 & 7500 & 3300 & 14400 \\
\hline $\begin{array}{l}\text { Optimised Blends of } \\
\text { Wheat Straws } \\
\text { Biochemical Routes } \\
\text { (Route iii and Route iv) }\end{array}$ & 2100 & 7500 & 4800 & 14400 \\
\hline
\end{tabular}
routes. These optimisation formulations were executed in General Algebraic Modelling System (GAMS) software using CPLEX as a solver. Table 12 and Table 13 tabulate all the optimisation results for the first and second parts, respectively. They were run by using the AMD A10-4600M APU processor.

Table 12. Results of optimal wheat straw blending.

As shown in Table 12, thermochemical routes used all wheat straws from sources 1 and 2, and $68.75 \%$ of source 3 for optimal blending. Meanwhile, biochemical routes used all wheat straws from sources 2 and 3, and only 58.33\% of source 1 for the same purpose. It should be mentioned that both thermochemical and biochemical routes had more comprehensive requirements for the feedstocks blending in practice; however, the intention in this study was to show how feedstocks blending qualities must be carefully analysed as they have direct effects to the process operations. Hydrogen to carbon ratio 
is one of the important characteristics of the thermochemical processes where biomass products would be used as fuel. Minimising this ratio means maximising the energy content (calorific value) of the wheat straw [18]. Wheat straw or blends of wheat straws with higher energy content are favoured especially when the bioethanol would be used as automotive biofuels. In the case of biochemical processes, ash content should be minimised to increase overall yields in the hydrolysis and fermentation processes [30].

Table 13. Comparison of profitability for the four routes.

\begin{tabular}{lllll}
\hline Route & Route i & Route ii & Route iii & Route iv \\
\hline Optimised Profit (\$/year) & 388530 & 489330 & 402750 & 472500 \\
\hline
\end{tabular}

Table 13 shows annual profitability for each of the four routes for wheat straw-tobioethanol production options. Clearly, route ii (torrefied pelletisation and gasification of the thermochemical route) gives the most profitable option, in view of the overall supply chain. In terms of bioethanol yields, both thermochemical routes produced 6701.4 tonnes per year, route iii produced 4890.6 tonnes per year, and route iv produced 5266.8 tonnes per year. Factors that could increase these productivities are such as the quests for suitable microbes [31], gasification techniques and performances [32], and operating conditions of acidic hydrolysis [33].

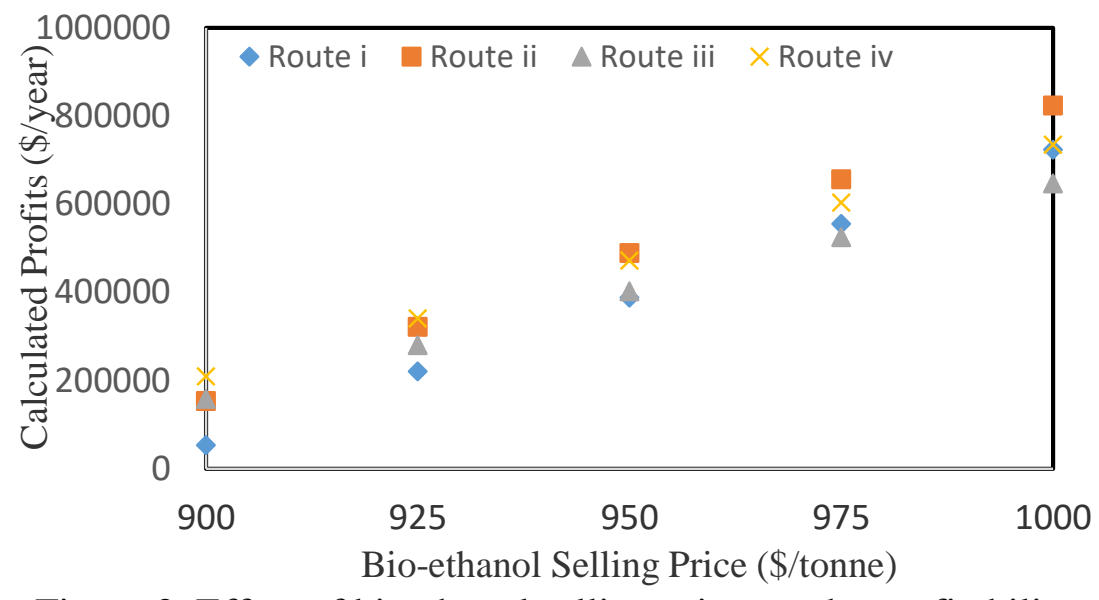

Figure 3. Effect of bioethanol selling prices to the profitability.

\section{Sensitivity Analysis}

The selling price of bioethanol and the wheat straw cost has the influence on economic profitability. Therefore, sensitivity analyses were done on both factors (bioethanol's price and wheat straw's cost) to study their effects on the profitability. Increasing the bioethanol selling price would increase profitability as shown in Figure 3 while increasing the wheat straw costs would decrease profitability as shown in Figure 4. For example, increasing bioethanol selling price from $\$ 950$ to $\$ 975$ (2.6\% increment) per tonne could increase the profitability by $43 \%, 34 \%, 30 \%$, and $28 \%$ for route i, ii, iii, and iv, respectively. Increasing wheat straw price from $\$ 85$ to $\$ 90$ (5.8\% increment) would bring the profitability decrease to $19 \%, 15 \%, 18 \%$, and $15 \%$ for route i, ii, iii, and iv respectively. Hence, this shows that bioethanol prices have more influence or are a more sensitive parameter that the wheat straw costs for determining overall profitability with only small change; i.e., at $2.6 \%$ increment. 


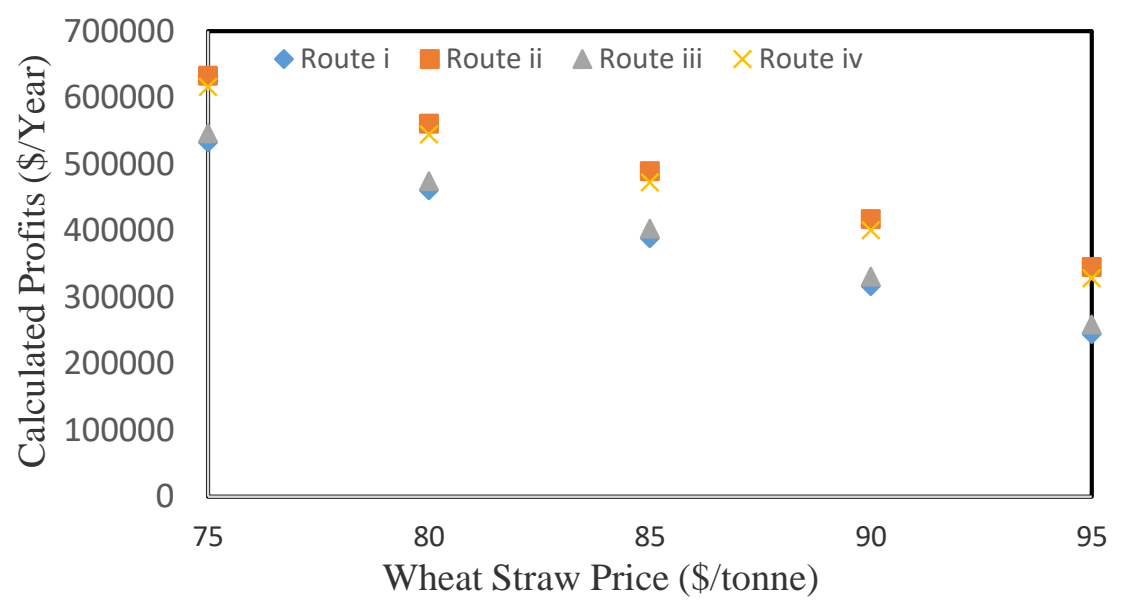

Figure 4. Effect of wheat straw costs to the profitability.

\section{CONCLUSIONS}

There are many ways of converting wheat straws to produce bioethanol which quantitative screening plays a major role. In this study, utilisation of biomass feedstock; i.e., the wheat straws to produce bioethanol has been discussed by comparing the annual profitability of four different processing routes; i) pelletisation and gasification, ii) torrefied pelletisation and gasification, iii) dilute acidic hydrolysis and fermentation, and iv) concentrated acidic hydrolysis and fermentation. In order to perform the comparison of screening, mathematical models of optimisation were formulated in the perspective of the supply chain, where relevant activities including pre-treatment, blending, and main processing were included. As for the blending, both proximate and ultimate analyses were recorded and shown to relate to the blending requirements for thermochemical and biochemical routes, respectively. The superstructure served as formulation guidance of the supply chain. Even though the parameters used in the developed model are rather conceptual, they are adequate to be used in this study for optimising wheat straw blending qualities and maximising the annual profit. It turned out that route ii (torrefied pelletisation and gasification) was the most profitable option, which gives $\$ 489,330$ per year for a 2 tonnes/hour plant capacity. Sensitivity analysis also showed that bioethanol price was an important parameter that could affect profitability even with small changes. For future work, it is recommended to use the developed model and extend it for more comprehensive qualities of feedstock blending requirements. It is also recommended to increase the capacities of each facility in the supply chain and obtain industrial data for model parameters so that the optimisation models may be practically used in any investment decision-making process that involves biomass as an alternative feedstock.

\section{ACKNOWLEDGEMENT}

The first author would like to acknowledge Universiti Malaysia Pahang for financial support through RDU1703710 research grant and University of Waterloo for the research and in-kind supports.

\section{REFERENCES}

[1] Georgieva TI, Mikkelsen MJ, Ahring BK. Ethanol production from wet-exploded wheat straw hydrolysate by thermophilic anaerobic bacterium 
Thermoanaerobacter BG1L1 in a continuous immobilized reactor. Applied Biochemistry and Biotechnology. 2008;145:99-110.

[2] He J, Zhang W. Techno-economic evaluation of thermo-chemical biomass-toethanol. Applied Energy. 2011;88:1224-32.

[3] Clarke S, Preto F. Biomass densification for energy production. A Report for Ontario Ministry of Agriculture Food and Rural Affairs. 2011.

[4] Salvachúa D, Prieto A, López-Abelairas M, Lu-Chau T, Martínez ÁT, Martínez MJ. Fungal pretreatment: An alternative in second-generation ethanol from wheat straw. Bioresource Technology. 2011;102:7500-6.

[5] Wang Q. Bioprocessing technologies in biorefinery for sustainable production of fuels, chemicals, and polymers. Green Processing and Synthesis2013. p. 637.

[6] Alex Marvin W, Schmidt LD, Benjaafar S, Tiffany DG, Daoutidis P. Economic optimization of a lignocellulosic biomass-to-ethanol supply chain. Chemical Engineering Science. 2012;67:68-79.

[7] Taouda H, Chabir R, Aarab L, Miyah Y, Errachidi F. Biomass and bioethanol production from date extract. Journal of Materials and Environmental Sciences. 2017;8:3093-8.

[8] Abdulrazik A, Elsholkami M, Elkamel A, Simon L. Multi-products productions from Malaysian oil palm empty fruit bunch (EFB): Analyzing economic potentials from the optimal biomass supply chain. Journal of Cleaner Production. 2017;168:131-48.

[9] Gelson T, Francis M. E, Raymond L. H. Integrative investment appraisal of a lignocellulosic biomass-to-ethanol industry. Journal of Agricultural and Resource Economics. 2003;28:611-33.

[10] Slade R, Bauen A, Shah N. The commercial performance of cellulosic ethanol supply-chains in Europe. Biotechnol Biofuels. 2009;2:3.

[11] Wang L, Littlewood J, Murphy RJ. Environmental sustainability of bioethanol production from wheat straw in the UK. Renewable and Sustainable Energy Reviews. 2013;28:715-25.

[12] Dunnett AJ, Adjiman CS, Shah N. A spatially explicit whole-system model of the lignocellulosic bioethanol supply chain: an assessment of decentralised processing potential. Biotechnol Biofuels. 2008;1:13.

[13] Demirbas A. Combustion characteristics of different biomass fuels. Progress in Energy and Combustion Science. 2004;30:219-30.

[14] Prabir B. Biomass gasification and pyrolysis: practical design and theory. Massachusetts, USA: Elsevier Inc.; 2010.

[15] Bryan M. J, James M. E. Thermochemical properties of biomass fuels. california agriculture. 1985.

[16] Jenkins BM, Baxter LL, Miles TR, Miles TR. Combustion properties of biomass. Fuel Processing Technology. 1998;54:17-46.

[17] Parikh J, Channiwala S, Ghosal G. A correlation for calculating HHV from proximate analysis of solid fuels. Fuel. 2005;84:487-94.

[18] Prabir B. Biomass gasification, pyrolysis and torrefaction: practical design and theory. Second Edition ed. San Diego, California: Elsevier Inc.; 2013.

[19] Sadhukhan J, Ng KS, Martinez E. Biorefineries and chemical processes: design, integration and sustainability analysis; 2014.

[20] Murillo-Alvarado PE, Ponce-Ortega JM, Serna-González M, Castro-Montoya AJ, El-Halwagi MM. Optimization of pathways for biorefineries involving the 
selection of feedstocks, products, and processing steps. Industrial \& engineering chemistry research. 2013;52:5177-90.

[21] Guidelines for Estimating Wheat Straw Biomass Production Costs. Manitoba Agriculture, Food and Rural Developement (MAFRD); 2016.

[22] Jim L. Cellulosic ethanol from agricultural residues. Think Ahead. Think Sunliquid., by BiofuelsDigest. 2015.

[23] Mupondwa E, Li X, Tabil L, Phani A, Sokhansanj S, Stumborg M, et al. Technoeconomic analysis of wheat straw densification in the Canadian Prairie Province of Manitoba. Bioresource Technology. 2012;110:355-63.

[24] Literature review and study energy market alternatives for commercially grown biomass in Ontario. Ontario, Canada: PPD Incorporated; 2011. Retrived from https://www.yumpu.com/en/document/view/24909059/literature-review-andstudy-energy-market-alternatives-ontario-.

[25] Mohammad J. T, Keikhosro K. Acid-Based hydrolysis processes for ethanol from lignocellulosic materials: A review. BioResources. 2007;2:472-99.

[26] George D. P, Maria C-N, Evan H, George S. Hydrogen production cost estimate using biomass gasification; 2011.

[27] Harold B, Bram vdD. "Biosyngas" key-intermediate in production of renewable transportation fuels, chemicals, and electricity: optimum scale and economic prospects of Fischer-Tropsch plants. In: 14th European Biomass Conference \& Exhibition 2005.

[28] Design Case Summary: Production of mixed alcohols from municipal solid waste via gasification. U.S Department of Energy; 2010.

[29] Subramani V, Gangwal SK. A review of recent literature to search for an efficient catalytic process for the conversion of syngas to ethanol. Energy and Fuels. 2008;22:814-39.

[30] Huang C, Lai C, Wu X, Huang Y, He J, Huang C, et al. An integrated process to produce bio-ethanol and xylooligosaccharides rich in xylobiose and xylotriose from high ash content waste wheat straw. Bioresource Technology. 2017;241:228-35.

[31] Mohd Azhar SH, Abdulla R, Jambo SA, Marbawi H, Gansau JA, Mohd Faik AA, et al. Yeasts in sustainable bioethanol production: A review. Biochemistry and Biophysics Reports. 2017;10:52-61.

[32] Babiker ME, Aziz ARA, Heikal M, Yusup S, Hagos FY. Experimental and simulation study on steam gasification of phoenix-dactylifera date palm seeds. International Journal of Automotive and Mechanical Engineering. 2016;13:320114.

[33] Mosier N, Wyman C, Dale B, Elander R, Lee YY, Holtzapple M, et al. Features of promising technologies for pretreatment of lignocellulosic biomass. Bioresource Technology. 2005;96:673-86. 